\title{
Changes in calf productivity and resistance as a result of using the lactulose-based feed additive
}

\author{
Yulia A. Voevodina, Tatyana V. Novikova, Vladimir B. Shevchuk, Anna I. Gnezdilova, Evgenia A. Fialkova, \\ Yulia V. Vinogradova, and Andrey A. Kuzin \\ Vologda State Dairy Farming Academy named after N.V. Vereshchagin, Vologda 160555, Russia
}

\begin{abstract}
Objective: the aim of the research is to make a comprehensive assessment of the prebiotic feed additive effect on calves. The experiment was carried out in work conditions on 10 black-and-white Holstein-cross calves at the age of 2 to 32 days. To conduct the experiment, an experimental group and a test group have been formed. Each group has included five milk-fed calves at the age of 2 days and older. All the calves have been given colostrum in their first 2-4 hours after birth and then they have been fed three times a day, at regular intervals. The following methods are used: clinical, microbiological, immunological and statistical. The article describes the prebiotic lactulose-based additive effect on the intestinal microbiocenosis development in one-month old calves and presents an assessment of humoral and cellular components of natural resistance in calves. The research results show a positive effect of the lactulose-based additive on the symbiotic microflora of the gastrointestinal tract that improves the natural resistance of the body and the physiological status of animals, reduces the disease duration and contributes to an increase in weight gain. After feeding the calves with the lactulose-containing preparation during their first month of life, the weight gain of each calf in the experimental group has been $21.8 \mathrm{~kg}$, or $+51 \%$ of the initial weight and in the test group $19.0 \mathrm{~kg}$, or $+41 \%$ of the initial weight. Feeding the additive has an impact on the two components of natural resistance: serum bactericidal activity in the experimental group calves has been higher by $17.8 \%$ and the phagocytosis activity has been higher by $30.5 \%$, compared to the test group calves. Feeding calves with the lactulose-containing additive helps reduce the illness duration, stimulates the increase in live weight and affects the natural resistance level of newborn animals positively.
\end{abstract}

\section{Introduction}

Despite the great advances in practical biology, many aspects of the dynamics of viability indicators during ontogenesis remain insufficiently studied [1]. It becomes clear that in the course of life, very often there can be changes in various parameters of the organism, which are far from favorable in all cases. In this regard, it is of great importance to identify the age characteristics of various indicators related to the regulatory systems of body $[2,3]$.

The elucidation of the specific features of the dynamics of functionally significant indicators in organisms caught in adverse environmental conditions is also of great interest $[4,5]$. One of these very frequent factors in productive animal factors is various gastrointestinal diseases [6].

The etiology of these diseases in calves is complex and diverse. The diseases can be caused by both viral, bacterial agents, protozoa, and the combined course of infection and invasion when the natural resistance is reduced [7, 8]. Numerous research works have revealed that the own microflora of humans and animals has a direct impact on the body state [9-11].

Some researchers call the microbiota as "a microbial organ", which has an immune stimulating effect as well as participates in the synthesis of vitamins, short-chain fatty acids, proteins and gases involved in regulating gastrointestinal peristalsis [12].

There are a lot of investigations focused on using probiotics for restoring the beneficial intestinal flora [13-16]. There is evidence that probiotic microorganisms introduced from outside are not able to be fixed in the gastrointestinal tract. They present only in the plankton form and are excreted within a short time [17]. Under these conditions, the optimal solution to the problem is using prebiotic preparations that develop optimal conditions for their own symbiotic microflora growth $[18,19]$.

Various substances, such as biotin, pantothenic acid, cysteine, riboflavin, amino sugar, oligosaccharides, etc., have a stimulating effect on the native microflora growth $[20,21]$. Lactulose is considered to be a prebiotic with the highest prebiotic index among those known $[22,23]$. Lactulose does not break down in the upper part of the gastrointestinal tract and passes immediately into the large intestine, after which it is used by bifid bacterium as a nutrient medium $[24,25]$.

Objective: the aim of the research is to make a comprehensive assessment of the prebiotic feed additive effect on calves.

Corresponding author: svetlanazsyu@ mail.ru 


\section{Materials and methods}

The study was conducted in strict accordance with the ethical principles established by the European Convention for the Protection of Vertebrate Animals used for experimental and other scientific purposes (adopted in Strasbourg on March 18, 1986 and confirmed in Strasbourg on June 15, 2006).

The research has been carried out in NovemberDecember, on a non-contagious farm in one of the agricultural enterprises in the Vologda region. The experiment has been carried out in work conditions on 10 black-and-white Holstein-cross calves at the age of 2 to 32 days. To conduct the experiment, an experimental group and a test group have been formed. Each group has included five milk-fed calves at the age of 2 days and older. All the calves have been given colostrum in their first 2-4 hours after birth and then they have been fed three times a day, at regular intervals.

All the animals have been kept according to the farm technology. The calves in the experimental group have been given $0.4 \mathrm{ml}$ of the additive per $1 \mathrm{~kg}$ of live weight in addition to the main diet for 30 days. The preparation has been given individually, using a dispenser.

The calves took into account body temperature, heart rate and respiratory movements. They also took into account the incidence of gastrointestinal diseases, the nature of feces, the safety, the duration of the disease, the effectiveness of treatment. Evaluation of live weight was carried out three times: during the formation of groups, in the middle and at the end of the experiment.

The intestinal microflora assessment has been carried out three times (at the age of 2, 16 and 32 days) by the microbiological method. The sample collection and study, identification of microorganisms have been carried out according to the existing methods [26]. The obtained results have been given concerning all microorganisms, in case of a comparative analysis in $1 g$ $\mathrm{CFU} / \mathrm{g}$, and in determining the limits of regulatory indicators - in CFU / g, that is colony-forming units per one gram of the test material.

The natural resistance level has been estimated by the state of the cellular component of protection (phagocytic activity of blood neutrophils) and by the state of the humoral component (serum bactericidal activity and serum lysozyme activity). The sample collection and study have been carried out according to the existing methods [27].

The results obtained are processed with a standard package of statistical programs.

\section{Results}

\subsection{The additive effect on the clinical state of the animals and their weight gain}

The health status of the animals has been under total control during the experiment. The experimental group animals as well as the test group animals have shown gastrointestinal disorder signs on the 4th-5th day of life. In the course of the treatment (rehydration therapy, antibiotics treatment), the diarrhea syndrome periodically worsened twice in the experimental group and three times in the test group. Fatal cases have not been registered. In the experimental group, the gastrointestinal tract activity has been stabilized faster on the 12th day in comparison to 20 day-long disease in the test group.

The average calf weight in the experimental group has been $42 \pm 1.52 \mathrm{~kg}$, and in the test group $46.2 \pm 3.7 \mathrm{~kg}$, the difference being out of statistical control. In the first 14 days of the experiment, the average daily weight gain of calves in the test group has been $10.3 \%$ higher compared to the experimental group $(0.457 \pm 0.141 \mathrm{~kg}$ and $0.41 \pm 0.22 \mathrm{~kg}$, respectively), the difference is insignificant and it is out of statistical control.

Two weeks later, the daily weight gain of calves in the experimental group has been $27 \%$ more compared to the test group $(940 \pm 0.21 \mathrm{~kg}$ and $0.74 \pm 0.18 \mathrm{~kg}$, respectively). During the 30 -day monitoring period, the average daily weight gain in the experimental group has been $0.703 \pm 0.1 \mathrm{~kg}$, compared to $0.61 \pm 0.084 \mathrm{~kg}$ in the test group, that is, the calves have gained weight by 15 $\%$ faster (figure 1 ).

\subsection{The additive effect on the intestinal microbiocenosis development in calves}

The intestinal microflora examination in two-day calves has revealed the number of typical Escherichia: in the test group it has been $5.77 \mathrm{lg} \mathrm{CFU/g}$ and in the experimental group - $6.08 \mathrm{lg} \mathrm{CFU} / \mathrm{g}$; no significant differences have been found. Yeast microflora has been also present.

The number of bifid bacterium has been $2,6 \times 10^{5}$ $\mathrm{CFU} / \mathrm{g}$ and $1.6 \times 10^{5} \mathrm{CFU} / \mathrm{g}$ and no significant differences have been found: $6.41 \mathrm{lg} \mathrm{CFU/g}$ and $6.20 \mathrm{lg} \mathrm{CFU/g}$ in the test group and in the experimental group, respectively. Enterococcus index has not been different in the groups and has amounted to $7.0 \mathrm{lg} \mathrm{CFU} / \mathrm{g}$ in all animals under the experiment. Lactobacilli growth has not been registered.

The number of bifid bacterium in the 16-day old calves of the test group has increased by $16 \%$ compared to the initial level (to $7.0 \mathrm{lg} \mathrm{CFU} / \mathrm{g}$ ), in one calf their number has decreased by $34 \%$ (to $4.0 \mathrm{lg} \mathrm{CFU} / \mathrm{g}$ ). In the experimental group, an increase in the number of bifid bacterium has averaged $38.5 \%$ (up to $8.2-9.1 \mathrm{~g} \mathrm{CFU/g}$ ). The number of lactobacilli in the experimental group calves has been $7.6 \mathrm{lg} \mathrm{CFU} / \mathrm{g}$, which is $52 \%$ more than the number of lactobacilli in the test group calves $(5.0 \mathrm{lg}$ $\mathrm{CFU} / \mathrm{g})$.

The number of enterococci in the test group has decreased from $7.0 \mathrm{lg}$ CFU/g to $4.39 \mathrm{lg}$ CFU/g and amounted $62 \%$ of the initial level. In the experimental group, the number of enterococci has decreased by $33 \%$ that is to $4.69 \mathrm{lg} \mathrm{CFU/g}$.

In the test group calves, an increase in Proteus number has been recorded up to $10^{4} \mathrm{CFU} / \mathrm{g}$. One calf of the experimental group also revealed the presence of Proteus in inoculation, but in a smaller amount of $10^{1}$ $\mathrm{CFU} / \mathrm{g}$. In the calves of the test group, conditionally 
pathogenic microorganisms of the Enterobacter and Citrobacter genera have been isolated in the amount up to $3.0 \mathrm{lg} \mathrm{CFU} / \mathrm{g}$.

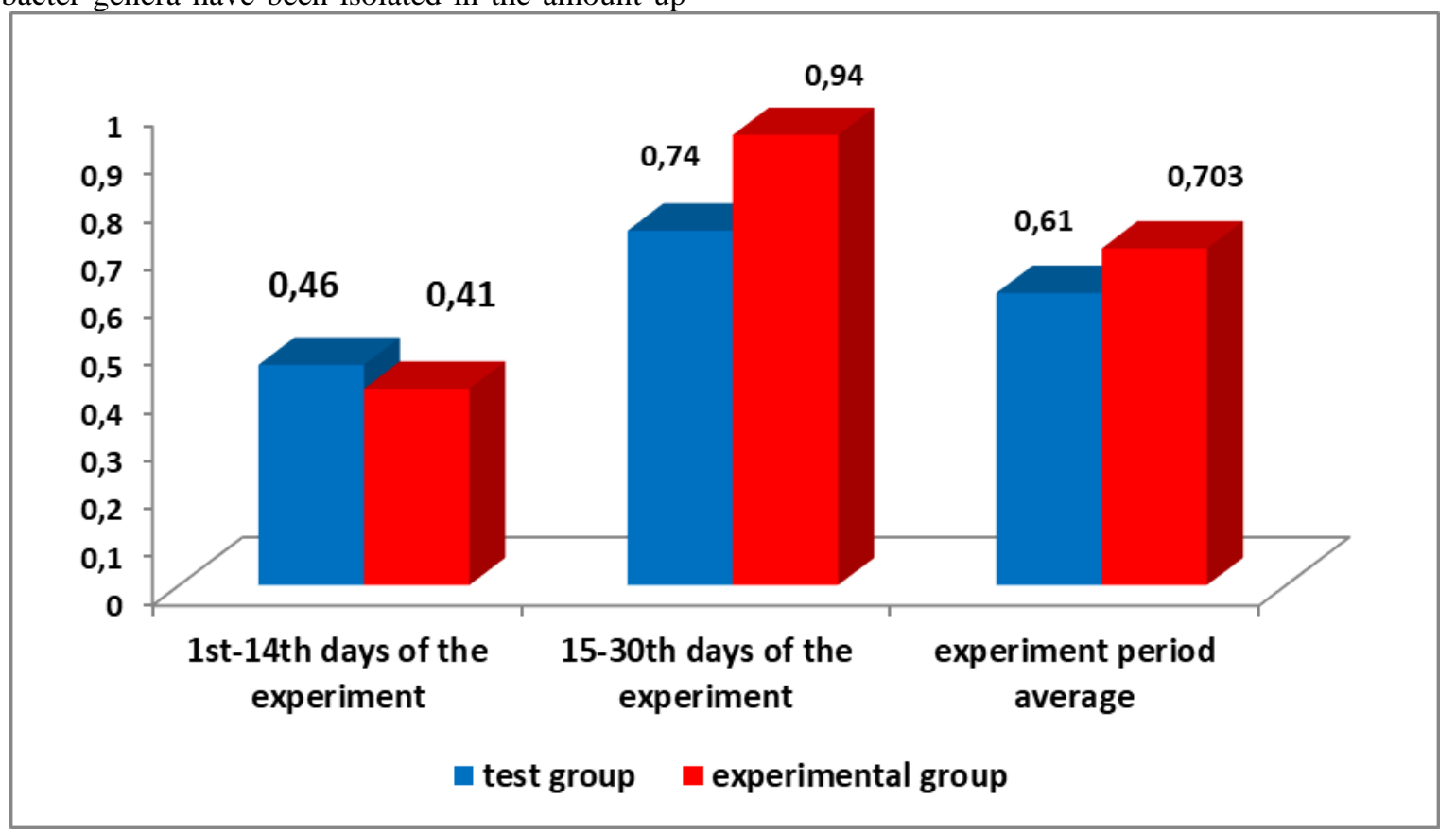

Fig. 1. Dynamics of weight gain in young animals during the experiment according to the observation periods.

Yeast-like and mold fungi have been found in all samples from test group calves in the amount up to $2.14 \mathrm{lg} \mathrm{CFU/g}$; in the experimental group, only one calf have revealed them in the amount not exceeding $2.0 \mathrm{lg}$ $\mathrm{CFU} / \mathrm{g}$, which is $7 \%$ lower than in the test group. The number of E. coli (typical) in the test group increased by $35 \%$ - from $5.77 \mathrm{lg}$ CFU/g to $7.7 \mathrm{lg}$ CFU / $\mathrm{g}$ and in the experimental group their number decreased by $16 \%-$ from $6.08 \mathrm{lg}$ CFU/g to $5.14 \mathrm{lg}$ CFU/g.

The third study at the age of 32 days has shown that in all samples from the test group calves, the number of bifid bacterium increased by $11 \%$ that is to $7.14 \mathrm{lg}$ $\mathrm{CFU} / \mathrm{g}$. In the experimental group, an increase in the number of bifid bacterium averaged $50 \%$, or to $9.32 \mathrm{lg}$ $\mathrm{CFU} / \mathrm{g}$. The number of lactobacilli in the experimental group calves has significantly increased to $9.3 \mathrm{lg} \mathrm{CFU} / \mathrm{g}$, which has been by $86 \%$ more compared to the test group $-5.0 \mathrm{lg} \mathrm{CFU} / \mathrm{g}$.

The number of enterococci in the test group has decreased to $5.0 \mathrm{lg} \mathrm{CFU} / \mathrm{g}$, which has accounted for $71 \%$ in comparison to the initial level. In the experimental group, the number of enterococci has also decreased by $53.8 \%$ or to $3.77 \mathrm{lg} \mathrm{CFU} / \mathrm{g}$.

\subsection{Estimation of natural resistance in animals}

The experimental group animals as well as the test group animals have undergone the nonspecific resistance estimation twice during the experiment according to the following items: serum bactericidal activity, serum lysozyme activity and phagocytic activity of blood neutrophils.

In the middle of the experiment (16 day-old calves) no significant difference in the serum bactericidal activity between the test group animals and the experimental group animals has been found $(69,6 \pm 7,9 \%$ и $66,2 \pm 11,0 \%$, respectively). At the end of the repetitive experiment (32 day-old calves), the serum bactericidal activity indicator has been higher by $17.8 \%$ in the experimental group calves than in the test group and has reached $91,27 \pm 7,16 \%$ in comparison to $77,4 \pm 4,08$ (the revealed difference is considerable and statistically significant, $\mathrm{P}>0.99$ ). The serum lysozyme activity indicator has been changing slightly in the test and experimental groups of animals and the difference between the groups has not been statistically significant.

Taking into account the changes in cellular protection of the calves, it is possible to note a significant increase in phagocytic activity (FA, \%) in the experimental group by $18.05 \%$, relative to the initial level. As for the test group, at the end of the experiment the phagocytic activity level of neutrophils has been higher by $30.5 \%$ (the difference is statistically significant $\mathrm{P}>0.99$ ) (Fig. 2).

By the end of the experiment, the phagocytic number (FN of microbial bodies) has increased in the both groups in comparison to the initial indicator: in the test group by $75 \%$, and in the experimental group by $39.6 \%$. During the entire experiment period, the phagocytosis intensity in the experimental group has been higher than in the test group by $51 \%$ in the middle of the experiment and by $20 \%$ at the end of the experiment (the difference has been significant, $\mathrm{P}>0.95$ ).

The phagocytic index (PI of microbial bodies) in the middle of the experiment has not been different in the groups. In the repetitive testing the experimental group calves have revealed an increase in the absorption capacity of neutrophils by $82 \%$, and the test group calves by $12 \%$. The difference between the groups at the end of the experiment has been $58.3 \%$. 


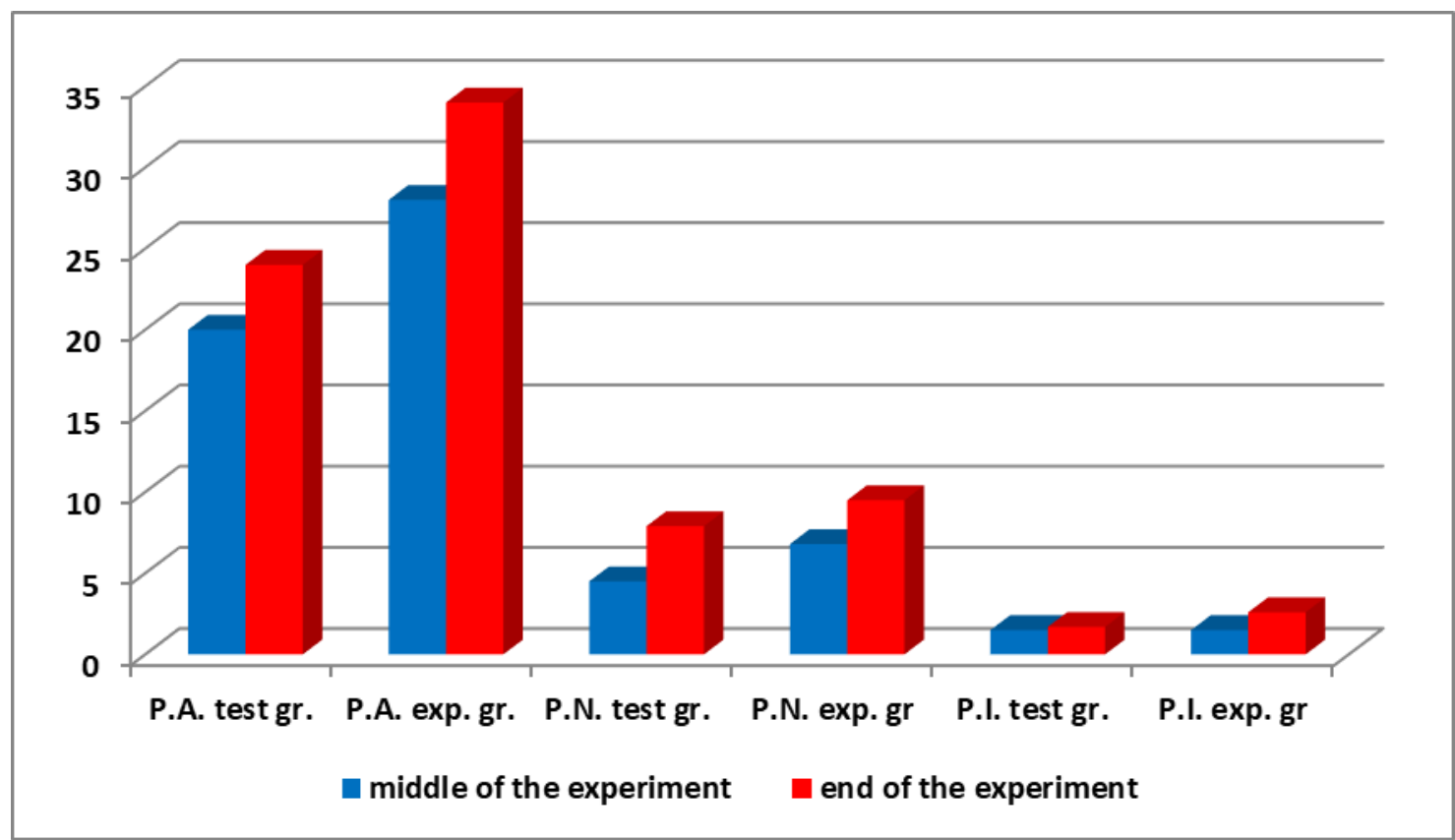

P.A. test gr. - phagocytic activity test group; P.A. exp. gr. - phagocytic activity experimental group P.N. test gr. - phagocytic number test group; P.N. exp. gr. - phagocytic number experimental group P.I. test gr. - phagocytic index test group; P.I. exp. gr. - phagocytic index experimental group

Fig. 2. Indicators of the cellular component protection

\section{Discussion}

Taking into account general physiological parameters, such as body temperature, pulse and respiration rates, the results of monitoring the clinical animal state have shown their compliance with the average optimal value for the young animals of this age [28].

By the end of the experiment, the experimental group calves have exceeded the test group calves in the average daily weight gain by $15 \%$; during the observation period, the increase in live weight of one calf in the experimental group was $+51 \%$, and in the test group + $41 \%$ compared to the initial weight.

The difference in the weight gain is evidently connected with the duration of the gastrointestinal disturbances - the period of disturbances in the experimental group animals has been shorter and, consequently, the digestibility of feed nutrients has been better.

Periodic exacerbation of the diarrhea syndrome may be the result of a long-term treatment with antibiotics, which have suppressed the pathogenic microflora and prevented the development of a complete microbiocenosis of the gastrointestinal tract. When using antibiotics, lactulose has provided a better survival of symbiotic microorganisms [5].

This fact is confirmed by the result of a microbiological examination of the calf intestine contents. The test group calves have revealed the coactant microcenosis imbalance (decrease of bifid bacterium and lactobacterium number) and, as a result, the overgrowth of conditionally pathogenic microflora and yeast-like fungi. Microorganisms of the Peptostreptococcus genus have been found in the test group calves. These germs are conditionally pathogenic and, according to some authors, can provoke gastrointestinal disorders [38]. Under conditions of an unformed microbiocenosis, the overgrowth of these microorganisms can be the reason for periodic tympany in the 1.0-1.5 month-old calves on this farm.

The microbiota examination has showed that the additive feeding contributes to a faster development of the balanced intestinal microbiocenosis in young animals. The symbiotic microflora development (lacto-and bifid bacterium) inhibits the colonization of the intestine by Escherichia, yeast and mold fungi, as well as other conditionally pathogenic microorganisms [29]. The calves with a balanced intestinal microbiocenosis assimilate feed components better and, consequently, gain in weight faster. The experimental group calves have caught up with the test group calves after two weeks of the experiment, and later they have surpassed them in the growth rate [30].

Quite a few sources emphasize that the symbiotic intestine microflora is able to influence the natural resistance level positively [14]. An estimation of the nonspecific resistance factors: humoral level (serum bactericidal activity, humoral serum lysozyme activity) and phagocytic level (phagocytic activity, phagocytic number and phagocytic index) have shown that the experimental group calves have had a higher level of natural nonspecific resistance $[31,32]$. Thus, the introduction of the prebiotic additive into the ration, indirectly through the formation of the gastrointestinal tract microbiota, has a positive effect on the natural resistance level of animals.

On the basis of the research results, it is possible to confirm a complex positive effect of the lactulosecontaining additive on young cattle in their first month of life [33, 34].

The positive effect of lactulose on the symbiotic microflora results in higher natural resistance, the physiological status of animals, reduces the disease duration and helps increase the weight gain [35]. 


\section{Conclusion}

After feeding the calves with the lactulose-containing preparation during their first month of life, the weight gain of each calf in the experimental group has been 21.8 $\mathrm{kg}$, or $+51 \%$ of the initial weight and in the test group $19.0 \mathrm{~kg}$, or $+41 \%$ of the initial weight. The calves fed with the lactulose-containing additive during their first month of life have had $22.5 \%$ more bifid bacterium than the calves in the test group. The experimental group calves have had $86 \%$ more lactobacilli compared to the test group calves. In general, the microbiota has been richer and the number of conditionally pathogenic microorganisms has been insignificant. In the background of antibiotic treatment, lactulose has ensured a better survival of symbiotic microorganisms. The Bifidobacterium flora activity growth in the experimental group has been $39 \%$ higher than in the test group. The Peptostreptococcus genus microorganisms, which are conditionally pathogenic, have been found in the test group calves. Feeding the additive has an impact on the two components of natural resistance: serum bactericidal activity in the experimental group calves has been higher by $17.8 \%$ and the phagocytosis activity has been higher by $30.5 \%$, compared to the test group calves. Feeding calves with the lactulose-containing additive helps reduce the illness duration, stimulates the increase in live weight and affects the natural resistance level of newborn animals positively.

\section{References}

1. N.V. Vorobyeva, I.N. Medvedev, Physiological Features Of Platelet Functioning In Calves of Holstein Breed During The Newborn, Res. J. of Pharmaceut., Biolog. and Chemical Sci., 9(6), 129-135 (2018)

2. Ju.L. Oshurkova, I.N. Medvedev, Functional Features Of Platelets In Newborn Calves Ayrshire Breed, Res. J. of Pharmaceut., Biolog. and Chemical Sci., 9(6), 313-318 (2018)

3. G.S. Mal, N.V. Vorobyeva, A.V. Makhova, I.N. Medvedev, I.I. Fayzullina, Features Of Physical Rehabilitation After Myocardial Infarction, Res. J. of Pharmaceut., Biolog. and Chemical Sci., 9(6), 280-285 (2018)

4. Ju.L. Oshurkova, I.N. Medvedev, Physiological Indicators Of Platelets In Ayrshire Calves During The Dairy Feeding Phase, Res. J. of Pharmaceut., Biolog. and Chemical Sci., 9(6), 171-176 (2018)

5. S.Yu. Zavalishina. The Functional State Of Vascular Hemostasis In Calves During The Neonatal Phase, Res. J. of Pharmaceut., Biolog. and Chemical Sci., 9(6), 1507-1512 (2018)

6. J. Behnsen, A. Perez-Lopez, S.P. Nuccio, M. Raffatellu, Exploiting Host immunity: the Salmonella paradigm, Trends Immunol, 36, 112-120 (2015) DOI: 10.1016/j.it.2014.12.003

7. B.M.M. Ahmer, J.S. Gunn, Interaction of Salmonella Spp. with the intestinal microbiota, Front.
Microbiol., $\quad 2, \quad 101 \quad$ (2011) DOI:

10.3389/fmicb.2011.00101

8. L.L. Almeida, I.C.S. Miranda, H.E. Hein, N.W. Santiago, E.F. Costa, F.S. Marks, C.R. Rodenbusch, C.W. Canal, L.G. Corbellini, Herdlevel risk factors for bovine viral diarrhea virus infection in dairy herds from Southern Brazil, Res. Vet. Sci., 93, 901-907 (2013) DOI: 10.1016/j.rvsc.2013.08.009

9. Metabolic syndrome and intestinal microflora: what is in common? Retrieved from: https://cyberleninka.ru/article/n/metabolicheskiysindrom-i-kishechnaya-mikroflora-chto-obschego

10. F. Sommer, F. Bäckhed, The gut microbiotamasters of host development and physiology, Nat. Rev. Microbiol., 11, 227-238 (2013)

11. V. Tremaroli, F. Bäckhed, Functional interactions between the gut microbiota and host metabolism, Nature, 489, 242-249 (2012)

12. S.P. Kovalev, V.A. Trushkin, Dynamics of some humoral indicators of innate immunity in calves with enteritis, Sci. Notes of the Kazan State Acad. of Veter. Med. named after N.E. Bauman, 1(221), 118-121 (2015)

13. S.Yu. Zavalishina, Physiology Of Antiaggregatory Manifestations of The Vascular Wall In Newborn Calves With Iron Deficiency, Receiving Metabolic Significant Effects, Res. J. of Pharmaceut., Biolog. and Chemical Sci., 9(6), 1530-1536 (2018)

14. Use of probiotics in feeding farm animals and birds, Retrieved from: https://cyberleninka.ru/article/n/ ispolzovanie-probiotikov-v-kormleniiselskohozyaystvennyh-zhivotnyh-i-ptits

15. S.Yu. Zavalishina, The Functional State Of Primary Hemostasis In Newborns Calves With Dyspepsia, Res. J. of Pharmaceut., Biolog. and Chemical Sci., 9(6), 1543-1549 (2018)

16. M.J. Alipour, J. Jalanka, T. Pessa-Morikawa, T. Kokkonen, R. Satokari, U. Hynönen, A. Iivanainen, M. Niku, The composition of the perinatal intestinal microbiota in cattle, Sci. Reports, 8 (2018)

17. S.Yu. Zavalishina, Dynamics Of The Functional State Of Platelet Functions In Newborn Calves Receiving Correction For Dyspepsia, Res. J. of Pharmaceut., Biolog. and Chemical Sci., 9(6), 1566-1572 (2018)

18. S.Yu. Zavalishina, Physiological Control Of The Vascular Wall Over Platelet-Induced Aggregation In Newborn Calves With Iron Deficiency, Res. J. of Pharmaceut., Biolog. and Chemical Sci., 9(6), 1601-1606 (2018)

19. S.Yu. Zavalishina, Functional Features Of Primary Hemostasis In Newborns Calves With Functional Disorders Of The Digestive System, Res. J. of Pharmaceut., Biolog. and Chemical Sci., 9(6), 1630-1636 (2018) 
20. G.R. Gibson, R. Fuller, Aspects of in vitro and In vivo research approaches directed toward identifying probiotics and prebiotics for human use, J. Nutr., 130(2), 391S-395S (2000)

21. J. Ghisolfi, Dietary fibre and prebiotics in infant formulas, Proc. Nutr. Soc., 62(l), 183-185 (2003)

22. S.Yu. Zavalishina, Elimination of platelet dysfunctions in newborn calves with functional digestive disorders, Res. J. of Pharmaceut., Biolog. and Chemical Sci., 9(6), 1650-1656 (2018)

23. M. Sinel'nikov, A.G. Khramtsov, I.A. Evdokimov, S.A. Ryabtseva, A.V. Serov, Lactose and its derivatives (Professiya Publ., St-Petersburg, 2007)

24. S.Yu. Zavalishina, Prevention Of Violations Of The Functional Status of Platelet Hemostasis In Newborn Calves With Functional Disorders Of The Digestive System, Res. J. of Pharmaceut., Biolog. and Chemical Sci., 9(6), 1672-1678 (2018)

25. V.A. Ponomarev, Bifidogenic concentrates with specified functional properties, Dairy industry, 1, 64 (2008)

26. Bacteriological diagnosis of intestinal dysbacteriosis, Manual (Astana, 2004)

27. P.N. Smirnov, M.I. Gulyukin, Yu.N. Fedorov, Natural resistance assessment of farm animals. New research methods of the veterinary medicine problems. Laboratory methods of studying infectious diseases of animals, 100-117 (RASKHN Publ., Moscow, 2008)

28. S.Yu. Zavalishina, Physiological Properties Of Platelets In Newborn Calves With Functional Disorders Of The Digestive System, Treated With The Sorbent "Ecos", Res. J. of Pharmaceut., Biolog. and Chemical Sci., 9(6), 1697-1702 (2018)
29. S.Yu. Zavalishina, The Dynamics of The Physiological Properties Of Hemostasis In Newborn Calves With Functional Disorders Of The Digestion Against The Background Of Their Consumption Of Needles Extract, Res. J. of Pharmaceut., Biolog. and Chemical Sci., 9(6), 1726-1731 (2018)

30. S.Yu. Zavalishina, Functional Features Of Vascular Hemostasis In Calves Of Dairy Nutrition, Res. J. of Pharmaceut., Biolog. and Chemical Sci., 9(6), 1754-1759 (2018)

31. S.Yu. Zavalishina, Functional Activity Of Vascular Hemostasis In Newborn Calves With Iron Deficiency, Res. J. of Pharmaceut., Biolog. and Chemical Sci., 9(6), 1490-1496 (2018)

32. S.Yu. Zavalishina, Physiological Features Of Primary Hemostasis In Newborns Calves With Functional Digestive Disorders, Res. J. of Pharmaceut., Biolog. and Chemical Sci., 9(6), 1514-1520 (2018)

33. S.Yu. Zavalishina, Functional Features Of Hemostasis In Calves of Dairy And Vegetable Nutrition, Res. J. of Pharmaceut., Biolog. and Chemical Sci., 9(6), 1544-1550 (2018)

34. S.Yu. Zavalishina, Functional Activity Of Primary Hemostasis In Calves During The First Year Of Life, Res. J. of Pharmaceut., Biolog. and Chemical Sci., 9(6), 1575-1581 (2018)

35. N.V. Vorobyeva, G.S. Mal, S.Yu. Zavalishina, T.I. Glagoleva, I.I. Fayzullina, Influence Of Physical Exercise On The Activity Of Brain Processes, Res. J. of Pharmaceut., Biolog. and Chemical Sci., 9(6), 240-244 (2018) 